\title{
A model of peer effects on instructor innovation adoption
}

\author{
Melody McConnell ${ }^{1 *}$ (D), Lisa Montplaisir ${ }^{2}$ and Erika G Offerdahl ${ }^{3}$ (D)
}

\begin{abstract}
A considerable body of evidence demonstrates that active, student-centered instructional practices are more effective than lecture-based, transmissionist approaches in improving undergraduate STEM learning. Despite this evidence and extensive reform initiatives, the majority of STEM instructors continue to teach didactically. Awareness of teaching innovations is widespread in some STEM disciplines, and instructors report trying new instructional approaches, yet the majority of them fail to continue using active learning strategies. Recent work suggests that the decision to experiment with and persist in using a teaching innovation is influenced more by instructors' perceived supports (e.g., access to curricular resources, supportive colleagues, positive departmental climate toward teaching) than perceived barriers. This commentary expands on the notion that the instructional decision-making process is personal and influenced by both individual and contextual factors to explicitly model the potential mechanisms by which peers encourage or discourage adoption of teaching innovations. We also discuss implications of this work for future research. We hope that this model will be helpful for work related to increasing the prevalence of active, student-centered instruction in undergraduate STEM.
\end{abstract}

Keywords: Innovation-decision, Instructional change, Peer interaction, University faculty

\section{Introduction}

In the continuing effort to improve undergraduate STEM (Science, Technology, Engineering, and Mathematics) education, the importance of active learning techniques, frequent formative assessment, and other research-based instructional practices is often highlighted (Bradforth et al. 2015; Committee on STEM Education of the National Science and Technology Council 2018; Freeman et al. 2014). Recent calls to action have stressed the need for more instructors to use research-based practices in undergraduate STEM, and extensive efforts continue to be made toward this goal (AAAS 2015; National Academies of Sciences 2018; Owens et al. 2018). Yet, there is still substantial evidence that many university STEM instructors continue to teach primarily didactically (Eagan et al. 2014; Stains et al. 2018). Even when instructors are aware of research-based practices and express positive attitudes and intent to use

\footnotetext{
* Correspondence: mel.mcconnell@gmail.com

${ }^{1}$ Division of Science \& Mathematics, Mayville State University, Mayville, ND 58257, USA

Full list of author information is available at the end of the article
}

them (Henderson et al. 2012; Lund and Stains 2015), they may implement the practices with modifications that decrease their effectiveness (Offerdahl et al. 2018; Stains and Vickrey 2017) or fail to persist in using them (Henderson et al. 2012; Offerdahl and Tomanek 2011).

Ultimately the decision of what and how to teach is affected by both personal and contextual factors (e.g., Andrews and Lemons 2015; Gess-Newsome et al. 2003; Sturtevant and Wheeler 2019). Research on change in higher education, and undergraduate STEM in particular, emphasizes the need to more fully understand individual teaching decisions within a broader institutional context if long-lasting changes are to be catalyzed and sustained (Austin 2011; Kezar 2014; Reinholz and Apkarian 2018). Indeed, undergraduate STEM instructors work within complex institutional systems that include formal and informal social networks (BouwmaGearhart et al. 2016; Kezar 2014). It may therefore seem intuitive that social interactions are a critical aspect of context that shapes the likelihood of change in higher education, yet this basic assumption has seldom been 
reflected explicitly in the change literature (Kezar 2014). Importantly, there has been little attention given to the mechanisms by which academic peers influence STEM instructors' decisions whether to adopt research-based teaching innovations in the classroom.

The aim of this commentary is to expand on existing notions of instructors' decision-making to explicitly account for how academic peers influence the implementation of research-based instructional practices. To this end, we have incorporated literature regarding innovation adoption (e.g., Andrews and Lemons 2015; Marbach-Ad and Hunt Rietschel 2016; Rogers 2003), peer influence (e.g., Dancy et al. 2016; Quardokus and Henderson 2015; Tomkin et al. 2019), departmental climate (e.g., Knight and Trowler 2000; Landrum et al. 2017; Lund and Stains 2015), and institutional change (e.g., Austin 2011; Kezar and Holcombe 2019; Marker et al. 2015; Reinholz and Apkarian 2018) to model three mechanisms through which peer interactions affect instructors' innovation adoption decisions. We conclude with implications and suggestions for future research.

\section{A model of peer effects on instructional innovation adoption}

The pedagogical decision-making process of undergraduate STEM instructors has been described using an innovation-decision framework (Andrews and Lemons 2015; Rogers 2003). The decision whether or not to adopt a teaching innovation (i.e., research-based instructional practice) includes several phases: finding out about an innovation (knowledge), forming opinions about it (persuasion), deciding (decision) whether or not to try it (implementation), and deciding whether or not to continue using it (continuation, or adoption). While the phases are thought to be consistent, the process is unique to each individual due to the numerous personal and contextual factors that come into play during each step (Andrews and Lemons 2015; Austin 1996; GessNewsome et al. 2003; Rogers 2003). The contextual factor we are focusing on here is interaction between peers (Kezar 2014).

Instructors interacting within an academic unit form a social network through which information and opinions can be shared (Andrews et al. 2016; Burt 2000; Grunspan et al. 2018; Kezar 2014; McConnell et al. 2019; Wasserman and Faust 1994). An individual's social network is known to be an influential factor in human behavior; the decisions an individual makes are heavily influenced by relationships and interactions (Dancy et al. 2016; Lane et al. 2019; Van Waes et al. 2015). Academic peer interactions facilitate the exchange of information, ideas, and awareness of teaching innovations, and provide encouragement and/or discouragement that can ultimately support or inhibit instructional change
(Andrews and Lemons 2015; Dancy et al. 2016; Henderson 2005; Lund and Stains 2015; Rogers 2003). The nature and frequency of interactions are influenced by the departmental and institutional context. Further, peer interactions also shape perceptions of context through communication of beliefs and practices (Grunspan et al. 2018; Pataraia et al. 2015; Roxå and Mårtensson 2009; Thomson and Trigwell 2018), thereby affecting perceptions of departmental supports and barriers and ultimately the likelihood of adopting teaching innovations (Bathgate et al. 2019; Kezar 2014; Lane et al. 2019; Shadle et al. 2017).

Similar to others, the model presented here builds from the assumption that an instructor's knowledge and affective state are key leverage points in the decisionmaking process (Fig. 1). Both an instructor's knowledge and affective state are activated in the innovationdecision process to make one of three decisions: implement an innovation (with or without some sort of reinvention or refinement), seek further information about an innovation, or reject the innovation (at least temporarily). Although peers have been identified in previous models of instructor decision-making, their role was subsumed under the larger construct of communication channels that can feed information into nearly any step of the innovation-decision process (Lund and Stains 2015; Rogers 2003; Sturtevant and Wheeler 2019). The model presented here is unique in that it accounts explicitly for potential mechanisms by which peer interactions influence knowledge and affective state in particular. We assert that peers act on an instructor's innovation-decision process in three specific ways: (1) they provide information to shape an instructor's

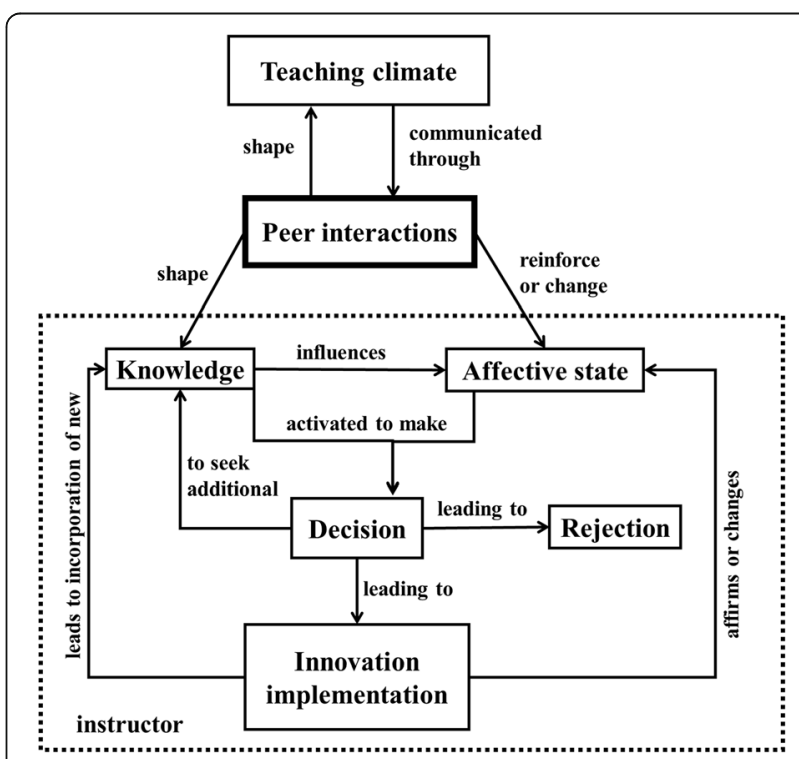

Fig. 1 A model of peer effects on instructor innovation adoption 
knowledge (e.g., Dancy et al. 2016; Henderson et al. 2011; Lane et al. 2019; Pataraia et al. 2015), (2) they reinforce or change an instructor's affective state (e.g., Andrews and Lemons 2015; Marbach-Ad and Hunt Rietschel 2016; Roxå and Mårtensson 2009; Sturtevant and Wheeler 2019; Wieman et al. 2013), and (3) they shape and communicate the teaching climate of the department, which can indirectly impact an instructor's affective state (e.g., Grunspan et al. 2018; Kezar 2014; Landrum et al. 2017; Lund and Stains 2015; Shadle et al. 2017). All downstream effects of peers (i.e., decisions by an instructor to implement or reject an innovation or seek more knowledge) are the result of one or more changes in either knowledge or affective state, or both.

Peer effects on an instructor's decision-making process can be innovation-positive, innovation-negative, or innovationneutral. This depends not only on what the peer does but also on the receiving instructor's personality, prior knowledge and affective state, perception of prevailing teaching climate, and features of the innovation itself (Andrews and Lemons 2015; Rogers 2003; Sturtevant and Wheeler 2019). An instructor interprets and processes peer input before using it to make decisions. For example, an instructor may hear a peer talking about using case studies to stimulate group discussion. Even if the peer is positive about their experience with case studies, the instructor hearing it may interpret that information in an innovation-negative way, e.g., if they do not have a favorable view of group discussion or already feel they have enough group discussion.

We conceive of "teaching climate" as encompassing not only the departmental context and microclimates within that context (Roxå and Mårtensson 2015; Schein 2010), but also the institutional and disciplinary contexts. Therefore, influential peer interactions are not constrained to the department, and can often take place outside departmental and disciplinary boundaries. Yet, we will focus most of the following narrative within the context of an academic unit (department), since undergraduate STEM instructors have regular interactions with their departmental peers, and academic departments are often the unit of instructional change initiatives (Andrews et al. 2016; Bush et al. 2016; Quardokus Fisher et al. 2019; Reinholz et al. 2019). However, we believe our model can also be applied beyond the departmental context.

No single model can account for every factor that influences innovation adoption. This model focuses on peer interactions as a mechanism for influencing an instructor's knowledge or affective state. An instructor's past and present experiences within and outside the classroom, including the environment for equity and diversity (e.g., Corneille et al. 2019; O'Meara et al. 2019), past professional development (or lack thereof) (e.g., Emery et al. 2020; Grunspan et al. 2018), and student input (e.g., Cook-Sather 2020; Wallace et al. 2019) shape their present knowledge and/or affective state (Emery et al. 2019; Shadle et al. 2017; Sturtevant and Wheeler 2019). The contribution of this model is the explicit linking of peer interactions as a mechanism for impacting knowledge and affect. For example, attributes of the innovation (e.g., trialability, ease of use; Rogers 2003) may affect likelihood of implementation but are not considered explicitly in the model. Rather, our model proposes that knowledge of these attributes may be ascertained in part by conversation with peers or by trying the innovation. In the following sections, we will discuss the individual components of our model in terms of the impacts of peer interactions.

\section{Teaching climate}

Undergraduate STEM instructors function within departmental and institutional contexts which considerably influence decisions about what and how to teach (e.g., Austin 2011; Landrum et al. 2017; Walter et al. 2014). Efforts to understand the conditions under which instructors are likely to consider and adopt alternative teaching approaches must therefore take into account the complexity of academic contexts (e.g., Austin 2011; BouwmaGearhart et al. 2016; Kezar 2014; Reinholz and Apkarian 2018). In particular, significant work has demonstrated that peer interactions and instructor behaviors are heavily dependent on the teaching climate, which can impact teaching and research identities, satisfaction with teaching, priority placed on teaching, and attitude toward teaching innovations (Grunspan et al. 2018; Knight and Trowler 2000; Quardokus Fisher et al. 2019; Schein 2010; Walter et al. 2014).We define climate as an emergent property of a department's prevailing culture, disciplinary history, interactions between members of the department, and outside influences such as institutional context and external stakeholders (Emery et al. 2019; Grunspan et al. 2018; Schein 2010; Schneider et al. 2013).

Each academic department has a unique complement of drivers and barriers, leading to a distinct departmental climate for teaching and instructional change with its own norms around teaching and social interactions (Lund and Stains 2015; Reinholz and Apkarian 2018; Roxå et al. 2011; Walter et al. 2014). Norms are defined as commonly known expectations or ways of doing things within a particular context-in this case, an academic department. Variation in climate and norms results in differential impacts on both individual instructor change and the potential for cultural change (Lund and Stains 2015; Reinholz and Apkarian 2018; Shadle et al. 2017; Sturtevant and Wheeler 2019). Recent studies indicate that a supportive department is highly correlated with the adoption of teaching innovations (Bathgate et al. 2019; Carbone et al. 2019) and that outcomes of 
change initiatives in STEM are dependent on departmental climates and norms (Chasteen et al. 2015; Sturtevant and Wheeler 2019).

Our model indicates that perceptions of climate communicated through peers can influence instructor decisions through reinforcing or changing an instructor's affective state, including satisfaction (with teaching in general, with a particular course or innovation, or generally their job satisfaction in the department), the motivation or priority placed on teaching, feelings of identity as a teacher and/or a researcher, curiosity or confidence about trying new teaching techniques, and beliefs about teaching (Landrum et al. 2017; Lund and Stains 2015; Schneider et al. 2013; Sturtevant and Wheeler 2019; Wieman et al. 2013; Woodbury and Gess-Newsome 2002).

For the model presented here, we focus mainly on the impact of peer interactions, so we include the role of peer interaction both in communicating climate to each other as well as in shaping climate. We further acknowledge that the climate includes norms around social interaction which impact the types of peer interaction that take place (Chasteen et al. 2015; Ma et al. 2018; Owens et al. 2018; Smolla and Akçay 2019). However, discussion of additional aspects of climate which may be directly perceived by instructors and influence their behavior (such as access to instructional resources, promotion and tenure policies and procedures, formal recognition of excellent teaching, and opportunities for professional development) is beyond the scope of this model.

\section{Knowledge}

Knowledge has previously been identified as a critical component of the innovation-decision process (Andrews and Lemons 2015; Rogers 2003). In our model, knowledge is defined as information an instructor has regarding a teaching innovation, its implementation, or the context within which it is to be implemented. Previous work has identified several types of knowledge that are important in teaching and instructor decision-making (e.g., Auerbach et al. 2018; Juhler 2017; Pataraia et al. 2015; Van Driel and Berry 2012) and explored the types of knowledge that can be exchanged through interaction with peers (Andrews and Lemons 2015; Dancy et al. 2016; Pataraia et al. 2015). As an example, pedagogical knowledge (e.g., knowledge of learning theory, understanding of the role of motivation and student affect in learning) would help instructors discern the most important components of an innovation and evaluate it (Auerbach et al. 2018; Auerbach and Andrews 2018; Jones and Moreland 2005; Van Driel and Berry 2012). Such knowledge could easily come from departmental or disciplinary peers if they teach similar topics (Pataraia et al. 2015; Quardokus and Henderson 2015). Another example of knowledge that may come from departmental peers is awareness of the existence of new innovations (Dancy et al. 2016; Lund and Stains 2015). Each of these types of knowledge can influence an instructor's decision directly (e.g., practical tips on how to use clickers) or by changing an instructor's affective state (e.g., perception that teaching innovation is a departmental norm).

All forms of knowledge are dynamic, continually changing based on personal experiences and information obtained from peers and other resources (Lund and Stains 2015; Marbach-Ad and Hunt Rietschel 2016; McAlpine et al. 1999; Rogers 2003). Therefore, knowledge is continually refined when information is received through any number of communication channels (e.g., interactions with peers, workshops, websites), as well as from reflection on classroom experiences (Andrews and Lemons 2015; McAlpine et al. 1999; Rogers 2003). Instructors often actively seek out additional knowledge, particularly when dissatisfied with their current approaches, in order to implement a technique (Lund and Stains 2015; Rogers 2003). Alternatively, knowledge can be shaped incidentally, as when a peer mentions a new technique during a conversation or a teaching method is discussed during a required professional development seminar.

An instructor who interacts regularly with peers potentially has access to more resources and may be better equipped to experiment with and adopt innovative teaching techniques (Benbow and Lee 2018; Burt 2000; Seibert et al. 2001; Van Waes et al. 2015). This may be particularly true for instructors who interact with peers that are education specialists or discipline-based education researchers (e.g., Andrews et al. 2016; Bush et al. 2006) Instructors are more likely to develop relationships with peers who are more similar to them (i.e., they share homophily), which can accelerate the exchange of information (Grunspan et al. 2014; Quardokus and Henderson 2015; Rogers 2003). However, while interactions between peers with homophily may be more efficient, the ideas may also be more limited in scope (Kezar 2014; Quardokus and Henderson 2015). Interactions between instructors with homophily within a department may produce micro-climates that share and reinforce a more narrow set of ideas (Roxå and Mårtensson 2015; Schein 2010; Tomkin et al. 2019). Further, instructors who value teaching innovations may be more likely to limit their interactions to those that share their same teaching beliefs (Lane et al. 2020). As a result, peers have the potential to both expand and constrain the trajectory of an individual instructor's knowledge development and capacity for innovation adoption.

\section{Affective state}

Previous models have implicitly identified an instructor's affective state to be influential in the decision-making 
process (Andrews and Lemons 2015; Gess-Newsome et al. 2003; Henderson 2005; Marbach-Ad and Hunt Rietschel 2016; McAlpine et al. 1999; Rogers 2003; Sturtevant and Wheeler 2019). We draw on these literatures to conceptualize an instructor's affective state to include their attitudes, values and goals as well as satisfaction, confidence, motivation, prioritization of teaching, and teaching identity. Like knowledge, affective state is constantly in flux depending on changes in the instructor's personal situation, departmental climate, new knowledge, and classroom experiences (Henderson 2005; McAlpine et al. 1999; Rogers 2003; Shadle et al. 2017). Since knowledge is affected by interactions with peers (e.g, hearing about a new assessment technique), the affective state of an instructor will be influenced by new information acquired by an instructor. Further, an instructor's perceptions of the teaching climate within their department and institution is obtained, in part, through interaction with peers, which will also impact the decision-making process (e.g., motivation to change may be lower in climates that value research over teaching) (Andrews and Lemons 2015; Bathgate et al. 2019; Knight and Trowler 2000; Lund and Stains 2015; Pugh and Hickson 2007). Through peer interactions, undergraduate STEM instructors can receive the encouragement necessary to decide to implement their knowledge of an instructional innovation (Andrews and Lemons 2015; Dancy et al. 2016; Lund and Stains 2015; Rogers 2003). Communities of practice provide knowledge as well as emotional and practical support shown to be important for sustained change (Guskey 2002; Henderson et al. 2011; Owens et al. 2018; Sirum and Madigan 2010; Wieman et al. 2013). Interactions with peers also provide opportunities for instructors to communicate instructional beliefs and practices, as well as perceptions of departmental norms (Grunspan et al. 2018; Pataraia et al. 2015; Roxå and Mårtensson 2009; Thomson and Trigwell 2018).

Peer interactions can influence the affective state of an instructor, and therefore their innovation-decision process, directly (e.g., increasing confidence in risktaking in the classroom), indirectly by communicating information (e.g., awareness of a new teaching technique), or by communicating and changing departmental norms (e.g., perceptions of a climate that values evidence-based teaching). Peers can also be a persistent barrier to innovation when they reinforce ideas about teaching norms that are not conducive to implementation of such innovations (Emery et al. 2019; Henderson et al. 2012; Lund and Stains 2015; Rogers 2003). Finally, interactions with peers are likely to interact with an instructor's personal and professional identity to affect an instructor's satisfaction with teaching and perceptions of support and security in taking instructional risks (e.g.,
Chesler and Young Jr 2007). For example, instructors who identify with persons excluded because of their ethnicity or race (PEERS; Asai 2020) or as a member of the LGBTQ+ community will potentially experience teaching differently than instructors who identify with historically overrepresented groups (e.g., Chesler and Young Jr 2007; Cooper et al. 2019). Furthermore, an instructor's cost-to-benefit analysis when weighing the time needed to adopt a teaching innovation versus time for research may be impacted by stereotype threat associated with identification in a particular social group (e.g., Milner and Hoy 2003; Ponjuan et al. 2011).

\section{Decision}

Both knowledge and affective state are activated to make a decision about whether or not to implement an innovation (McAlpine et al. 1999; Sturtevant and Wheeler 2019; Trowler and Cooper 2002). Our model suggests university STEM instructors form and re-form opinions about innovations through a cyclical and iterative process. Persuasion has been represented as a separate step in early innovation-decision models (Rogers 2003), but we follow Andrews and Lemons (2015) by not including it as a separate step. We acknowledge that persuasion is part of the process of opinion forming by which knowledge influences affective state and these together initiate decision-making.

Decision-making can take place just once or many times. Attitudes formed about an innovation (including a belief that the innovation is better than current practice) do not always produce changes in classroom practices due to other affective influences and barriers, including departmental climate and norms (Buehl and Beck 2014; Lund and Stains 2015; Offerdahl and Tomanek 2011; Sturtevant and Wheeler 2019). Our model identifies three possible outcomes of the decisionmaking step: implementing an innovation as prescribed or with some modifications (Offerdahl et al. 2018; Stains and Vickrey 2017), seeking more information about the innovation, and rejecting the innovation.

\section{Implementation}

Undergraduate STEM transformation efforts aim to increase the frequency with which instructors decide to implement research-based instructional practices. Some instructors will decide to enact a research-based instructional practice (e.g., peer instruction, team-based learning, process-oriented guided inquiry learning) exactly as they first became aware of it. But more commonly instructors make changes, particularly following their own experiences with implementation and reflection (Henderson 2005; Rogers 2003; Stains and Vickrey 2017). Refinements or whole-scale reinventions can happen before or after trying innovations in an effort to obtain 
or preserve instructor satisfaction (Marbach-Ad and Hunt Rietschel 2016; McAlpine et al. 1999).

Once an instructor has implemented a research-based instructional practice, their own classroom experience becomes a primary source of information to evaluate the innovation (Andrews and Lemons 2015; Guskey 2002; McAlpine et al. 1999; Sturtevant and Wheeler 2019). Instructors may also seek input from peers who can help them reflect on their experiences and suggest changes for future implementation (Bandura 2001; Rogers 2003; Roxå and Mårtensson 2009). Perceptions of the teaching climate may also influence their reflections on the efficacy of the instructional practice and subsequent decisions (Lund and Stains 2015; Morris et al. 2015).

Long-term adoption, also known as confirmation (Rogers 2003) or continuation (Henderson 2005) ideally incorporates reflection on past classroom experiences on repeated cycles. Instructors continually decide to implement an innovation iteratively, making refinements as necessary based on results of previous iterations as well as new information they obtain (Andrews and Lemons 2015; Henderson 2005; Henderson et al. 2012; MarbachAd and Hunt Rietschel 2016; McAlpine et al. 1999; Trowler and Cooper 2002).

\section{Seeking additional knowledge}

Often an instructor seeks additional information before deciding to implement a new teaching practice (Lund and Stains 2015; Marbach-Ad and Hunt Rietschel 2016; Rogers 2003). Seeking knowledge can be motivated by dissatisfaction with current teaching practice, prioritization of change (Andrews and Lemons 2015; Pataraia et al. 2015; Roxå and Mårtensson 2009; Sturtevant and Wheeler 2019), or departmental climates in which talking about teaching is the norm (Owens et al. 2018; Roxå and Mårtensson 2009; Van Waes et al. 2015). Instructors may seek teaching-related resources or reach out to a peer viewed as possessing expertise in order to get ideas for improving teaching or addressing a particular problem (Henderson 2005).

The decision to seek additional information is generally a conscious one. In some cases, information about a teaching innovation is acquired passively. For example, a peer may share with another instructor their experiences in trying a new teaching innovation. The instructor will therefore have received information about the innovation without actively seeking it, but not have enough information to implement the innovation themselves (Lund and Stains 2015). In this regard, instructors can actively seek to increase knowledge about an innovation, or may inadvertently receive information from a peer. While this model explicitly recognizes the likelihood of seeking behavior, we also recognize that implementation decisions can happen based on initial awareness only, without gathering additional information (Guskey 2002; Henderson 2005).

\section{Rejection}

The third and final potential decision is to reject the innovation, which can happen with or without first trying the teaching innovation (Henderson et al. 2011, 2012; Rogers 2003). Rejection means a temporary or permanent end to the innovation-decision process for that innovation, although rejected innovations can be reconsidered at a later date, particularly if an instructor's circumstances or attributes change (Rogers 2003). However, it is important to note that even rejected innovations can lead to changes in an instructor's initial knowledge and/or affective state. This happens because there is awareness of the rejected innovation and some kind of opinion was formed of it (Andrews and Lemons 2015; Rogers 2003). If the innovation was tried before being rejected, then classroom experiences also lead to incorporation of knowledge and potential changes in affective state (Marbach-Ad and Hunt Rietschel 2016).

\section{Discussion and future directions}

A vast literature base already indicates that the rates of innovation adoption vary with environment (BouwmaGearhart et al. 2016; Grunspan et al. 2018; Lund and Stains 2015), instructors' perceptions of departmental climate impact their willingness to use innovations (Bathgate et al. 2019; Landrum et al. 2017; Shadle et al. 2017), and persistence in using innovations is enhanced by a supportive community (Owens et al. 2018; Thomson and Trigwell 2018; Tomkin et al. 2019; Wieman et al. 2013). We have developed a model that explicates the role of peer interaction in facilitating (or inhibiting) university STEM instructors' innovation adoption decisions. Importantly, this model allows us to be more specific in understanding and predicting the effects of perturbations to the departmental social network. In this section, we propose three research questions arising from our model that will further our understanding of the conditions for widespread adoption of innovative teaching techniques.

\section{What are the qualities of peer interactions that are likely to facilitate innovation adoption?}

Peers are a likely source of teaching information for instructors (Dancy et al. 2016; Pataraia et al. 2015; Rogers 2003), and it is unlikely an instructor will implement a teaching innovation with very little information about it (Lund and Stains 2015; Rogers 2003). Therefore, our model indicates that seeking additional information would tend to increase the likelihood of implementation (Fig. 1). While we recognize that implementation decisions can happen without seeking additional 
information, we expect this outcome to be relatively uncommon. In contrast, rejecting an innovation on the basis of limited information may be the easier decision to make for instructors, unless they have very high levels of confidence and/or motivation (Rogers 2003). Rejection without seeking is thus expected to happen much more often than implementation without seeking.

Therefore, one might hypothesize that instructors who talk to peers more frequently, and/or are in environments that encourage this type of interaction, will be more likely to implement teaching innovations (Lane et al. 2019; McConnell et al. 2019). Peers can provide the information (knowledge) or perspective (affective state) necessary to make a decision to implement an innovation or to reflect on the implementation experience. Furthermore, peers can increase initial opportunities to adopt innovations by providing awareness of new ideas to each other (Dancy et al. 2016). There is some evidence of a correlation between peer interactions and innovation adoption in instructional settings already (McConnell et al. 2019; Middleton et al. 2015; Riihimaki and Viskupic 2020; Van Waes et al. 2015).

It would also be reasonable to predict that departmental climates that encourage teaching interaction and seeking behavior would, by extension, produce more innovation adoption because they would increase the likelihood of supportive peer interactions. Similarly, peers within a supportive microclimate or community of practice would be more likely to both try and continue using innovations than peers without this support (Roxå et al. 2011; Tomkin et al. 2019; Wieman et al. 2013).

Peer interactions may also have an innovation-negative effect, depending on the departmental context and the particular peers involved, thereby increasing decisions to reject a teaching innovation or to remain satisfied with current teaching practices. Future research should strive to discern the types of interactions that are beneficial for adoption of innovations and the conditions under which those interactions are most beneficial.

\section{How do departmental climates and subclimates moderate the effects of peer interactions?}

When an instructor seeks out or obtains information from a peer, the decision they make with that information will be mediated not only by their personal situation and characteristics but also their perceptions of the teaching climate (Austin 1996; Kezar 2014; Lund and Stains 2015; Reinholz et al. 2019). As noted above, climate is an emergent property that is shaped, in part, by interactions between members of a social network (Emery et al. 2019; Grunspan et al. 2018; Schein 2010; Schneider et al. 2013). Therefore, teaching climate and peer interactions are difficult to fully disentangle because perceptions of climate are influenced by the understanding that is constructed through peer interactions. Our model (Fig. 1) indicates that teaching climate as communicated through peer interactions can impact instructor affective state. There are certainly other ways in which an individual gains information that shapes perceptions of the teaching climate (Reinholz and Apkarian 2018). We hypothesize that an instructor's perception of teaching climate as a whole, gained directly and through peers, likely has a larger impact on motivation, priority, identity, and general attitude toward teaching and teaching innovation than any isolated interaction with a peer because climate is in part an emergent property of many peers, and because of the additional aspects of climate that exert influence on an instructor (Emery et al. 2019; Grunspan et al. 2018; Reinholz and Apkarian 2018). For example, departmental climates typically have a long-standing historical cultural element that helps shape the identity of an instructor, which a single peer typically does not (Grunspan et al. 2018; Lund and Stains 2015; Owens et al. 2018; Reinholz and Apkarian 2018). Additionally, while departmental climate affects an instructor and all of their peers, individual peer interactions only impact one or a few instructors at a time. Thus, we would expect instructors' perceptions of teaching climate to be more predictive of their innovation adoption than any single peer interaction in a typical department.

Yet because departmental climate is also intertwined with peer interactions, we might expect an additive effect in supportive teaching climates. Departments with teaching-supportive norms would communicate that teaching is valued and encourage interactions about teaching. In such a context, we expect that supportive peers could become a much more relevant influence that reinforces risk-taking and innovation (Kezar 2014; Roxå and Mårtensson 2009). In this situation, norms and peer interactions may have a synergistic, mutually reinforcing impact, and groups of peers may be more influential toward initiating change.

Subgroups can form within a department that may have different norms than those that prevail in the surrounding departmental climate (Roxå and Mårtensson 2015; Schein 2010). In fact, organizational cultures actually consist of many overlapping cultures (Henderson et al. 2011; Schein 2010). Such subgroups are predicted to impact instructor affective state, just as does the prevailing climate in the department. Some aspects of the departmental climate could be reinforced by subculture norms, while others are subverted. For example, within a department in which lecture has broad acceptance as the instructional norm, a subgroup of instructors interested in active learning may form, interacting with each other to share ideas and support each other in trying active learning techniques. We would expect that instructors in 
that subgroup and adjacent to it would be more likely to implement innovations even though their department is unsupportive, since they are receiving social support to do so from the subgroup (Kezar 2014; Roxå and Mårtensson 2015). However, they might be less likely to persist in using the innovations than if they were in a supportive departmental climate, since they are lacking the norms and institutional structural supports that would come with such a climate (Reinholz and Apkarian 2018). Conversely, a department in which the primary instructional norm is active learning may contain a pocket of resistant or skeptical instructors who reinforce each other's decisions to continue using lecture, or not to try new teaching innovations. Such instructors may be less likely than those outside that subgroup to be implementing innovations, even though they teach within an innovation-friendly department, because they are receiving social support not to use innovations (Kezar 2014; Roxå and Mårtensson 2015).

\section{What is the relationship between peer social networks and teaching climate in supporting adoption of teaching innovations?}

Social and teaching norms impact the affective state of all members of a department. Norms impact how instructors interact with each other and therefore the structure of the social network within the department (Chasteen et al. 2015; Smolla and Akçay 2019), which will ultimately impact how instructors receive both information and support. For example, it is probable that seeking behavior would be mediated by the teaching climate and social norms in a department. In department climates with norms that encourage collaboration around teaching, peers would be more likely to demonstrate seeking behavior (Lund and Stains 2015; Roxå and Mårtensson 2009). Seeking behavior would not only influence that particular instructor's decision-making process, but variation in seeking behavior would also affect the frequency and structure of interactions in the network. Conversely, strong norms of academic freedom and individuality, for example, would likely depress interactions among colleagues and discourage seeking behavior.

Peer interactions also feed back into the emergent property that is departmental climate (Emery et al. 2019; Grunspan et al. 2018; Schein 2010; Schneider et al. 2013). Therefore, peer interactions can initiate or perpetuate departmental climates that influence the likelihood for widespread adoption of teaching innovation. Formally, instructional change initiatives could find ways to encourage teaching interaction and collaboration, such as through the formation of communities of practice (Owens et al. 2018; Roxå and Mårtensson 2009; Tomkin et al. 2019), leveraging interactions with opinion leaders (Andrews et al. 2016; Knaub et al. 2018), or by developing the relational expertise of change agents (Quardokus Fisher et al. 2019). When collaboration is encouraged, peers who work together would more readily share pedagogical content knowledge, how-to tips, and ideas and would be able to support each other through changes. We expect that departments and change initiatives that find ways to facilitate teachingcentered communities would experience positive results with instructor innovation adoption, which would be enhanced if reinforced by social and teaching norms. Conversely, if departmental history, norms, and reward structures strongly favor lecture, incorporating communities of practice alone may not have as much of an impact, and such communities would need to be carefully designed to overcome the impacts of these deep-seated cultural norms. Future research could identify ways in which communities of peers could be designed to modify the teaching climate within a department, and the ways in which peer interactions may make a teaching climate more or less conducive to adoption of teaching innovations.

\section{Conclusion}

In this commentary, we have expanded on previous models of instructional decision-making in undergraduate STEM teaching to propose probable mechanisms by which interactions with academic peers affect the adoption of research-based instructional practices. This model has potential utility for both researchers and those looking to support instructional change in undergraduate STEM education. We hope that the model will be tested and validated in a variety of situations and contexts and used to more fully elucidate the specific effects of peer interactions on an instructor's decision-making process. This can be done by studying (1) how peers interact with each other, the types of information they exchange, and how teaching climate influences interaction patterns, and (2) individual instructor decisions and the impacts they perceive from peers and their departmental teaching climate. Many such studies are already being done, with examples cited above in this commentary. However, leveraging the model presented here to explicitly focus on the ways in which peer interactions influence instructor decision-making may have distinct advantages. As researchers accumulate data on the relative importance of different peer interactions and outcomes, they will be able to predict and explain how different types of peer interactions in different teaching climates may mediate the impact of change initiatives on individual instructors.

As we continue to seek widespread change in STEM education, future work should more closely examine the context within which instructors are working and how 
that affects their decision-making. In particular, the effects of context on the decision-making processes of instructors that identify with science persons excluded because of their ethnicity or race (PEERs) or who identify as LGBTQ+ should be explored as their experiences have significant implications for inclusion in STEM (Asai 2020; Cooper et al. 2020). We will then be able to suggest beneficial changes at the institutional, departmental, and individual level that will help instructors adopt student-centered instructional practices in an evidence-based way. The model presented here will be a useful framework for administrators, peer change agents, and individual instructors to maximize adoption of beneficial instructional innovations and minimize potential negative effects of unsupportive teaching climates and peers. Administrators and change agents can use this model to think about the types of peer interactions that are likely to be beneficial and how those can be encouraged within a given departmental climate in the service of instructional change. Professional development programs can take into account the social context and suggest ways instructors can succeed in pedagogical change, and work within institutions to incorporate communities of practice that will maximize beneficial interactions and the spread of effective teaching innovations. In sum, understanding the role of academic peers in fostering instructional innovation adoption will help change agents continue to transform the landscape of undergraduate STEM education.

\section{Abbreviations}

STEM: Science, Technology, Engineering, and Mathematics

\section{Acknowledgements \\ The authors thank Jessie Arneson and Kurt Williams for thoughtful comments during the development of this manuscript. The authors also extend our greatest expressions of gratitude to our anonymous reviewers whose thoughtful and critical feedback produced a significantly improved commentary.}

\section{Authors' contributions}

MM developed an initial draft of the model and wrote an initial draft of the manuscript. All three authors contributed to refining the model and editing and expanding the manuscript. Each author read and approved the final product.

\section{Funding}

This work was supported in part by a research fellowship awarded by the North Dakota State University Graduate School for the STEM Education graduate program. The funding body did not have a role in design or writing of the manuscript.

\section{Availability of data and materials}

Data sharing is not applicable to this article as no datasets were generated or analyzed during the current study.

\section{Competing interests}

The authors declare that they have no competing interests.

\section{Author details}

'Division of Science \& Mathematics, Mayville State University, Mayville, ND 58257, USA. ${ }^{2}$ Department of Biological Sciences, North Dakota State
University, Fargo, ND 58108, USA. ${ }^{3}$ School of Molecular Biosciences, Washington State University, Pullman, WA 99164-7520, USA.

Received: 22 May 2020 Accepted: 6 October 2020

Published online: 12 November 2020

\section{References}

AAAS (2015). Vision and change: Chronicling change, inspiring the future. Washington, DC: AAAS

Andrews, T. C., Conaway, E. P., Zhao, J., \& Dolan, E. L. (2016). Colleagues as change agents: How department networks and opinion leaders influence teaching at a single research university. CBE-Life Sciences Education, 15(2), ar15. https://doi.org/https://doi.org/10.1187/cbe.15-08-0170

Andrews, T. C., \& Lemons, P. P. (2015). It's personal: Biology instructors prioritize personal evidence over empirical evidence in teaching decisions. CBE-Life Sciences Education, 14(1), ar7. https://doi.org/https://doi.org/10.1187/cbe.1405-0084

Asai, D. J. (2020). Race Matters. Cell, 181(4), 754-757. https://doi.org/https://doi. org/10.1016/j.cell.2020.03.044

Auerbach, A. J., Higgins, M., Brickman, P., \& Andrews, T. C. (2018). Teacher knowledge for active-learning instruction: Expert-Novice Comparison Reveals Differences. CBE_Life Sciences Education, 17(1), ar12. https://doi.org/https:// doi.org/10.1187/cbe.17-07-0149

Auerbach, A. J. J., \& Andrews, T. C. (2018). Pedagogical knowledge for activelearning instruction in large undergraduate biology courses: A large-scale qualitative investigation of instructor thinking. International Journal of STEM Education, 5(1), 19. https://doi.org/https://doi.org/10.1186/s40594-018-0112-9

Austin, A. E. (1996). Institutional and departmental cultures: The relationship between teaching and research. New Directions for Institutional Research, 1996(90), 57-66. https://doi.org/https://doi.org/10.1002/ir.37019969009

Austin, A. E. (2011). Promoting evidence-based change in undergraduate science education: A paper commissioned by the National Academies National Research Council Board on Science Education. http://sites.nationalacademies.org/cs/ groups/dbassesite/documents/webpage/ dbasse_072578.pdf

Bandura, A. (2001). Social cognitive theory: An agentic perspective. Annual Review of Psychology, 52(1), 1-26. https://doi.org/https://doi.org/10.1146/annurev. psych.52.1.1

Bathgate, M. E., Aragón, O. R., Cavanagh, A. J., Frederick, J., \& Graham, M. J. (2019). Supports: A key factor in faculty implementation of evidence-based teaching. CBE-Life Sciences Education, 18(2), ar22. https://doi.org/https://doi.org/10. $1187 /$ cbe. 17-12-0272

Benbow, R. J., \& Lee, C. (2018). Teaching-focused social networks among college faculty: Exploring conditions for the development of social capital. Higher Education. https://doi.org/https://doi.org/10.1007/s10734-018-0331-5

Bouwma-Gearhart, J., Sitomer, A., Quardokus Fisher, K., Smith, C., \& Koretsky, M. (2016). Studying organizational change: Rigorous attention to complex systems via a multi-theoretical research model. 2016 ASEE Annual Conference \& Exposition Proceedings. 2016 ASEE Annual Conference \& Exposition, New Orleans, Louisiana. https://doi.org/https://doi.org/10.18260/p.25945

Bradforth, S. E., Miller, E. R., Dichtel, W. R., Leibovich, A. K., Feig, A. L., Martin, J. D., Bjorkman, K. S., Schultz, Z. D., \& Smith, T. L. (2015). University learning: Improve undergraduate science education. Nature, 523(7560), 282-284. https://doi.org/https://doi.org/10.1038/523282a

Buehl, M. M., \& Beck, J. S. (2014). The relationship between teachers' beliefs and teachers' practices. International handbook of research on teachers' beliefs. Routledge. ch5 https://doi.org/https://doi.org/10.4324/9780203108437.

Burt, R. S. (2000). The network structure of social capital. Research in Organizational Behavior, 22, 345-423. https://doi.org/https://doi.org/10.1016/ S0191-3085(00)22009-1

Bush, S. D., Pelaez, N. J., Rudd, J. A., Stevens, M. T., Williams, K. S., Allen, D. E., \& Tanner, K. D. (2006). On hiring science faculty with education specialties for your science (not education) department. CBE - Life Sciences Education, 5(4), 297-305. https://doi.org/https://doi.org/10.1187/cbe.06-09-0189

Bush, Seth D., Rudd, J. A., Stevens, M. T., Tanner, K. D., \& Williams, K. S. (2016). Fostering change from within: Influencing teaching practices of departmental colleagues by science faculty with education specialties. PLOS ONE, 11(3), e0150914. https://doi.org/https://doi.org/10.1371/journal.pone. 0150914

Carbone, A. Drew, S, Ross, B, Ye, J, Phelan, L, Lindsay, K. \& Cottman, C. (2019). A collegial quality development process for identifying and addressing barriers 
to improving teaching. Higher Education Research \& Development, $0(0), 1-15$ https://doi.org/https://doi.org/10.1080/07294360.2019.1645644

Chasteen, S. V., Wilcox, B., Caballero, M. D., Perkins, K. K., Pollock, S. J., \& Wieman, C. E. (2015). Educational transformation in upper-division physics: The Science Education Initiative model, outcomes, and lessons learned. Physical Review Special Topics - Physics Education Research, 11(2). https://doi.org/https://doi. org/10.1103/PhysRevSTPER.11.020110

Chesler, M., \& Young Jr, A. A. (2007). Faculty members' social identities and classroom authority. New Directions for Teaching and Learning, 2007(111), 1119. https://doi.org/https://doi.org/10.1002/tl.281

Committee on STEM Education of the National Science \& Technology Council. (2018). Charting a course for success: America's strategy for STEM education. Executive Office of the President of the United States.

Cook-Sather, A. (2020). Respecting voices: How the co-creation of teaching and learning can support academic staff, underrepresented students, and equitable practices. Higher Education, 79(5), 885-901. https://doi.org/https:// doi.org/10.1007/s10734-019-00445-w

Cooper, K. M., Auerbach, A. J. J., Bader, J. D., Beadles-Bohling, A. S., Brashears, J. A., Cline, E., Eddy, S. L., Elliott, D. B., Farley, E., Fuselier, L., Heinz, H. M., Irving, M., Josek, T., Lane, A. K, Lo, S. M., Maloy, J., Nugent, M., Offerdahl, E., Palacios-Moreno, J., ... Brownell, S. E. (2020). Fourteen recommendations to create a more inclusive environment for LGBTQ+ individuals in academic biology. CBE_Life Sciences Education, 19(3), es6. https:/doi.org/https://doi.org/10.1187/cbe.20-04-0062

Cooper, K. M., Brownell, S. E., \& Gormally, C. (2019). Coming out to the class: Identifying factors that influence college biology instructor decisions about revealing their lgbq identities in class. Journal of Women and Minorities in Science and Engineering, 25(3), 261-282. https://doi.org/https://doi.org/10 1615/JWomenMinorScienEng.2019026085

Corneille, M., Lee, A., Allen, S., Cannady, J., \& Guess, A. (2019). Barriers to the advancement of women of color faculty in STEM: The need for promoting equity using an intersectional framework. Equality, Diversity and Inclusion: An International Journal, 38(3), 328-348. https://doi.org/https://doi.org/10.1108/ EDI-09-2017-0199

Dancy, M., Henderson, C., \& Turpen, C. (2016). How faculty learn about and implement research-based instructional strategies: The case of peer instruction. Physical Review Physics Education Research, 12(1). https://doi.org/ https://doi.org/10.1103/PhysRevPhysEducRes.12.010110

Eagan, K., Stolzenberg, E. B., Lozano, J. B., Aragon, M. C., Suchard, M. R., \& Hurtado, S. (2014). Undergraduate teaching faculty: The 2013-2014 HERI Faculty Survey. Los Angeles: Higher Education Research Institute, UCLA.

Emery, N. C., Maher, J. M., \& Ebert-May, D. (2019). Studying professional development as part of the complex ecosystem of STEM higher education. Innovative Higher Education. https://doi.org/https://doi.org/10.1007/s10755019-09475-9

Emery, N. C., Maher, J. M., \& Ebert-May, D. (2020). Early-career faculty practice learner-centered teaching up to 9 years after postdoctoral professional development. Science Advances, 6(25), eaba2091. https://doi.org/https://doi. org/10.1126/sciadv.aba2091

Freeman, S., Eddy, S. L., McDonough, M., Smith, M. K., Okoroafor, N., Jordt, H., \& Wenderoth, M. P. (2014). Active learning increases student performance in science, engineering, and mathematics. Proceedings of the National Academy of Sciences, 111(23), 8410-8415. https://doi.org/https://doi.org/10.1073/pnas. 1319030111

Gess-Newsome, J., Southerland, S. A., Johnston, A., \& Woodbury, S. (2003). Educational reform, personal practical theories, and dissatisfaction: The anatomy of change in college science teaching. American Educational Research Journal, 40(3), 731-767.

Grunspan, D. Z., Kline, M. A., \& Brownell, S. E. (2018). The lecture machine: a cultural evolutionary model of pedagogy in higher education. CBE-Life Sciences Education, 17(3), es6. https:/doi.org/https:/doi.org/10.1187/cbe.17-12-0287

Grunspan, D. Z., Wiggins, B. L., \& Goodreau, S. M. (2014). Understanding classrooms through social network analysis: A primer for social network analysis in education research. CBE-Life Sciences Education, 13(2), 167-178. https://doi.org/https://doi.org/10.1187/cbe.13-08-0162

Guskey, T. R. (2002). Professional development and teacher change. Teachers and Teaching, 8(3), 381-391. https://doi.org/https://doi.org/10.1080/ 135406002100000512

Henderson, C. (2005). The challenges of instructional change under the best of circumstances: A case study of one college physics instructor. American Journal of Physics, 73(8), 778-786. https://doi.org/https://doi.org/10.1119/1. 1927547
Henderson, C., Beach, A., \& Finkelstein, N. (2011). Facilitating change in undergraduate STEM instructional practices: An analytic review of the literature. Journal of Research in Science Teaching, 48(8), 952-984. https://doi. org/https://doi.org/10.1002/tea.20439

Henderson, C., Dancy, M., \& Niewiadomska-Bugaj, M. (2012). Use of research-based instructional strategies in introductory physics: Where do faculty leave the innovationdecision process? Physical Review Special Topics - Physics Education Research, 8(2). https:/doi.org/https:/doi.org/10.1103/PhysRevSTPER.8.020104

Jones, A., \& Moreland, J. (2005). The importance of pedagogical content knowledge in assessment for learning practices: A case-study of a wholeschool approach. Curriculum Journal, 16(2), 193-206. https://doi.org/https:// doi.org/10.1080/09585170500136044

Juhler, M. V. (2017). Educating pre-service science teachers; promoting PCK development through the use of lesson study combined with content representation. Norway: University of Stavanger https://uis.brage.unit.no/uisxmlui/handle/11250/2437229.

Kezar, A. J. (2014). Higher education change and social networks: A review of research. The Journal of Higher Education, 85(1), 91-125. https://doi.org/ https://doi.org/10.1080/00221546.2014.11777320

Kezar, A. J., \& Holcombe, E. M. (2019). Leveraging multiple theories of change to promote reform: an examination of the AAU STEM initiative. Educational Policy, 089590481984359. https://doi.org/https://doi.org/10.1177/ 0895904819843594

Knaub, A. V., Henderson, C., \& Fisher, K. Q. (2018). Finding the leaders: an examination of social network analysis and leadership identification in STEM education change. International Journal of STEM Education, 5(1). https://doi. org/https://doi.org/10.1186/s40594-018-0124-5

Knight, P. T., \& Trowler, P. R. (2000). Department-level cultures and the improvement of learning and teaching. Studies in Higher Education, 25(1), 69 83. https://doi.org/https://doi.org/10.1080/030750700116028

Landrum, R. E., Viskupic, K., Shadle, S. E., \& Bullock, D. (2017). Assessing the STEM landscape: The current instructional climate survey and the evidence-based instructional practices adoption scale. International Journal of STEM Education, 4(1), 25. https://doi.org/https://doi.org/10.1186/s40594-017-0092-1

Lane, A. Kelly, McAlpin, J. D., Earl, B., Feola, S., Lewis, J. E., Mertens, K, Shadle, S. E., Skvoretz, J., Ziker, J. P., Couch, B. A., Prevost, L. B., \& Stains, M. (2020). Innovative teaching knowledge stays with users. Proceedings of the National Academy of Sciences, 202012372. https://doi.org/https:/doi.org/10.1073/pnas.2012372117

Lane, A. Kelly, Skvoretz, J., Ziker, J. P., Couch, B. A., Earl, B., Lewis, J. E., McAlpin, J. D., Prevost, L. B., Shadle, S. E., \& Stains, M. (2019). Investigating how faculty social networks and peer influence relate to knowledge and use of evidence-based teaching practices. International Journal of STEM Education, 6(1), 28. https://doi.org/https://doi.org/10.1186/s40594-019-0182-3

Lund, T. J., \& Stains, M. (2015). The importance of context: an exploration of factors influencing the adoption of student-centered teaching among chemistry, biology, and physics faculty. International Journal of STEM Education, 2(1). https://doi.org/https://doi.org/10.1186/s40594-015-0026-8

Ma, S., Herman, G. L., Tomkin, J. H., Mestre, J. P., \& West, M. (2018). Spreading teaching innovations in social networks: The bridging role of mentors. Journal for STEM Education Research, 1(1-2), 60-84. https://doi.org/https://doi. org/10.1007/s41979-018-0002-6

Marbach-Ad, G., \& Hunt Rietschel, C. (2016). A case study documenting the process by which biology instructors transition from teacher-centered to learner-centered teaching. CBE_Life Sciences Education, 15(4), ar62. https:// doi.org/https://doi.org/10.1187/cbe.16-06-0196

Marker, A., Pyke, P., Ritter, S., Viskupic, K., Moll, A., Landrum, R. E., Roark, T., \& Shadle, S. (2015). Applying the CACAO change model to promote systemic transformation in STEM. Transforming institutions: Undergraduate STEM education for the 21st century, 176

McAlpine, L., Weston, C., Beauchamp, C., Wiseman, C., \& Beauchamp, J. (1999). Building a metacognitive model of reflection. Higher Education, 37(2), 105-131.

McConnell, M., Montplaisir, L., \& Offerdahl, E. (2019). Meeting the conditions for diffusion of teaching innovations in a university STEM department. Journal for STEM Education Research, 1-26. https://doi.org/https://doi.org/10.1007/ s41979-019-00023-w

Middleton, J. A., Krause, S., Beeley, K., Judson, E., Ernzen, J., \& Culbertson, R. (2015). Examining the relationship between faculty teaching practice and interconnectivity in a social network. 2015 IEEE Frontiers in Education Conference (FIE), 1-7. https://doi.org/https://doi.org/10.1109/FIE.2015.7344179

Milner, H. R., \& Hoy, A. W. (2003). A case study of an African American teacher's self-efficacy, stereotype threat, and persistence. Teaching and Teacher 
Education, 19(2), 263-276. https://doi.org/https://doi.org/10.1016/50742051X(02)00099-9

Morris, M. W., Hong, Y., Chiu, C., \& Liu, Z. (2015). Normology: Integrating insights about social norms to understand cultural dynamics. Organizational Behavior and Human Decision Processes, 129, 1-13. https://doi.org/https://doi.org/10. 1016/j.obhdp.2015.03.001

National Academies of Sciences. (2018). Indicators for monitoring undergraduate STEM education. National Academies Press. https://doi.org/https://doi.org/10 $17226 / 24943$

O'Meara, K., Lennartz, C. J., Kuvaeva, A., Jaeger, A., \& Misra, J. (2019). Department conditions and practices associated with faculty workload satisfaction and perceptions of equity. The Journal of Higher Education, 90(5), 744-772. https:// doi.org/https://doi.org/10.1080/00221546.2019.1584025

Offerdahl, E. G., McConnell, M., \& Boyer, J. (2018). Can I have your recipe? Using a fidelity of implementation (FOI) framework to identify the key ingredients of formative assessment for learning. CBE-Life Sciences Education, 17(4), es16. https://doi.org/https://doi.org/10.1187/cbe.18-02-0029

Offerdahl, E. G., \& Tomanek, D. (2011). Changes in instructors' assessment thinking related to experimentation with new strategies. Assessment \& Evaluation in Higher Education, 36(7), 781-795. https://doi.org/https://doi.org/10.1080/ 02602938.2010 .488794

Owens, M. T., Trujillo, G., Seidel, S. B., Harrison, C. D., Farrar, K. M., Benton, H. P., Blair, J. R., Boyer, K. E., Breckler, J. L., Burrus, L. W., Byrd, D. T., Caporale, N., Carpenter, E. J., Chan, Y.-H. M., Chen, J. C., Chen, L., Chen, L. H., Chu, D. S., Cochlan, W. P., ... Reiness, C. G. (2018). Collectively improving our teaching: attempting biology department-wide professional development in scientific teaching. CBE-Life Sciences Education, 17(1), ar2. https://doi.org/https://doi. org/10.1187/cbe.17-06-0106

Pataraia, N., Margaryan, A., Falconer, I., \& Littlejohn, A. (2015). How and what do academics learn through their personal networks. Journal of Further and Higher Education, 39(3), 336-357. https://doi.org/https://doi.org/10.1080/ 0309877X.2013.831041

Ponjuan, L., Conley, V. M., \& Trower, C. (2011). Career stage differences in pretenure track faculty perceptions of professional and personal relationships with colleagues. The Journal of Higher Education, 82(3), 319-346. https://doi. org/https://doi.org/10.1353/jhe.2011.0015

Pugh, D., \& Hickson, D. (2007). People in organizations. In Writers on Organizations (6th ed., pp. 129-162). SAGE Publications, Inc. https://doi.org/https://doi.org/ 10.4135/9781483329628

Quardokus Fisher, K., Sitomer, A., Bouwma-Gearhart, J., \& Koretsky, M. (2019). Using social network analysis to develop relational expertise for an instructional change initiative. International Journal of STEM Education, 6(1). https://doi.org/https://doi.org/10.1186/s40594-019-0172-5

Quardokus, K., \& Henderson, C. (2015). Promoting instructional change: Using social network analysis to understand the informal structure of academic departments. Higher Education, 70(3), 315-335. https://doi.org/https://doi.org/ 10.1007/s10734-014-9831-0

Reinholz, D. L., \& Apkarian, N. (2018). Four frames for systemic change in STEM departments. International Journal of STEM Education, 5(1), 3. https://doi.org/ https://doi.org/10.1186/s40594-018-0103-x

Reinholz, D. L., Matz, R. L., Cole, R., \& Apkarian, N. (2019). STEM is not a monolith: A preliminary analysis of variations in STEM disciplinary cultures and implications for change. CBE-Life Sciences Education, 18(4), mr4. https://doi. org/10.1187/cbe.19-02-0038

Riihimaki, C. A., \& Viskupic, K. (2020). Motivators and inhibitors to change: Why and how geoscience faculty modify their course content and teaching methods. Journal of Geoscience Education, 68(2), 115-132. https://doi.org/ https://doi.org/10.1080/10899995.2019.1628590

Rogers, E. M. (2003). Diffusion of innovations. Free Press.

Roxå, T., \& Mårtensson, K. (2009). Significant conversations and significant networks - exploring the backstage of the teaching arena. Studies in Higher Education, 34(5), 547-559. https://doi.org/https://doi.org/10.1080/ 03075070802597200

Roxå, T., \& Mårtensson, K. (2015). Microcultures and informal learning: A heuristic guiding analysis of conditions for informal learning in local higher education workplaces. International Journal for Academic Development, 20(2), 193-205. https://doi.org/https://doi.org/10.1080/1360144X.2015.1029929

Roxå, T., Mårtensson, K, \& Alveteg, M. (2011). Understanding and influencing teaching and learning cultures at university: A network approach. Higher Education, 62(1), 99-111. https://doi.org/https://doi.org/10.1007/s10734-010-9368-9

Schein, E. H. (2010). Organizational culture and leadership. John Wiley \& Sons.
Schneider, B., Ehrhart, M. G., \& Macey, W. H. (2013). Organizational climate and culture. Annual Review of Psychology, 64(1), 361-388. https://doi.org/https:// doi.org/10.1146/annurev-psych-113011-143809

Seibert, S. E., Kraimer, M. L., \& Liden, R. C. (2001). A social capital theory of career success. The Academy of Management Journal, 44(2), 219-237. https://doi.org/ https://doi.org/10.2307/3069452

Shadle, S. E., Marker, A., \& Earl, B. (2017). Faculty drivers and barriers: Laying the groundwork for undergraduate STEM education reform in academic departments. International Journal of STEM Education, 4(1). https://doi.org/ https://doi.org/10.1186/s40594-017-0062-7

Sirum, K. L., \& Madigan, D. (2010). Assessing how science faculty learning communities promote scientific teaching. Biochemistry and Molecular Biology Education, 38(3), 197-206. https://doi.org/https://doi.org/10.1002/bmb.20364

Smolla, M., \& Akçay, E. (2019). Cultural selection shapes network structure. Science Advances, 5(8), eaaw0609. https://doi.org/https://doi.org/10.1126/sciadv.aaw0609

Stains, M., Harshman, J., Barker, M. K., Chasteen, S. V., Cole, R., DeChenne-Peters, S. E., Eagan, M. K., Esson, J. M., Knight, J. K., Laski, F. A., Levis-Fitzgerald, M., Lee, C. J., Lo, S. M., McDonnell, L. M., McKay, T. A., Michelotti, N., Musgrove, A., Palmer, M. S., Plank, K. M., ... Young, A. M. (2018). Anatomy of STEM teaching in North American universities. Science, 359(6383), 1468-1470. https://doi.org/ https://doi.org/10.1126/science.aap8892

Stains, M., \& Vickrey, T. (2017). Fidelity of implementation: An overlooked yet critical construct to establish effectiveness of evidence-based instructional practices. CBE-Life Sciences Education, 16(1), rm1. https://doi.org/https://doi. org/10.1187/cbe.16-03-0113

Sturtevant, H., \& Wheeler, L. (2019). The STEM Faculty Instructional Barriers and Identity Survey (FIBIS): Development and exploratory results. International Journal of STEM Education, 6(1), 35. https//doi.org/https:/doi.org/10.1186/s40594-019-0185-0

Thomson, K. E., \& Trigwell, K. R. (2018). The role of informal conversations in developing university teaching? Studies in Higher Education, 43(9), 1536-1547. https://doi.org/https://doi.org/10.1080/03075079.2016.1265498

Tomkin, J. H., Beilstein, S. O., Morphew, J. W., \& Herman, G. L. (2019). Evidence that communities of practice are associated with active learning in large STEM lectures. International Journal of STEM Education, 6(1). https://doi.org/ https://doi.org/10.1186/s40594-018-0154-z

Trowler, P., \& Cooper, A. (2002). Teaching and learning regimes: Implicit theories and recurrent practices in the enhancement of teaching and learning through educational development programmes. Higher Education Research \& Development, 21(3), 221-240. https://doi.org/https:/doi.org/10.1080/0729436022000020742

Van Driel, J. H., \& Berry, A. (2012). Teacher professional development focusing on pedagogical content knowledge. Educational Researcher, 41(1), 26-28. https:// doi.org/https://doi.org/10.3102/0013189X11431010

Van Waes, S., Van den Bossche, P., Moolenaar, N. M., De Maeyer, S., \& Van Petegem, P. (2015). Know-who? Linking faculty's networks to stages of instructional development. Higher Education, 70(5), 807-826. https://doi.org/ https://doi.org/10.1007/s10734-015-9868-8

Wallace, S. L., Lewis, A. K., \& Allen, M. D. (2019). The state of the literature on student evaluations of teaching and an exploratory analysis of written comments: Who benefits most? College Teaching, 67(1), 1-14. https://doi.org/ https://doi.org/10.1080/87567555.2018.1483317

Walter, E., Beach, A., Henderson, C., \& Williams, C. (2014). Describing instructional practice and climate: Two new instruments. In Transforming Institutions: Undergraduate STEM Education for the 21st Century. (Vol. 24)

Wasserman, S., \& Faust, K. (1994). Social network analysis: Methods and applications (pp. xxxi, 825). Cambridge University Press. https://doi.org/ https://doi.org/10.1017/CBO9780511815478

Wieman, C., Deslauriers, L., \& Gilley, B. (2013). Use of research-based instructional strategies: How to avoid faculty quitting. Physical Review Special Topics Physics Education Research, 9(2). https://doi.org/https://doi.org/10.1103/ PhysRevSTPER.9.023102

Woodbury, S., \& Gess-Newsome, J. (2002). Overcoming the paradox of change without difference: A model of change in the arena of fundamental school reform. Educational Policy, 16(5), 763-782. https://doi.org/https://doi.org/10. $1177 / 089590402237312$

\section{Publisher's Note}

Springer Nature remains neutral with regard to jurisdictional claims in published maps and institutional affiliations. 